\title{
Assessment on the research trend of low-carbon energy technology investment: A bibliometric analysis
}

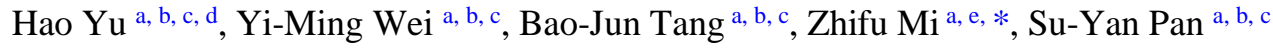 \\ a. Center for Energy and Environmental Policy Research, Beijing Institute of Technology, Beijing 100081, China \\ b. School of Management and Economics, Beijing Institute of Technology, Beijing 100081, China \\ c. Collaborative Innovation Center of Electric Vehicles in Beijing, Beijing 100081, China \\ d. Visitor of Energy Policy Research Group, University of Cambridge, Cambridge CB2 1AG, UK \\ e. School of International Development, University of East Anglia, Norwich NR4 7TJ, UK
}

\begin{abstract}
Based on databases of Science Citation Index Expanded (1981-present) and Social Sciences Citation Index (2002-present), this paper applies the bibliometric method to analyze the scientific publications of low-carbon energy technology investment. By characterizing the basic information of the publications, we found: the historical development process is clearly divided into two stages; the field of low-carbon energy technology investment ${ }^{1}$ has entered a stage of rapid development; the strength of developed countries is far greater than that of developing countries; the comprehensive strength of the United States ranks the first in the field, followed by UK and Denmark and only China and Turkey are developing countries among the top 15 countries; the auctorial collaboration degree in this field shows a clear upward trend, but institutional and national collaboration degrees are steady and relatively low. In addition, distributions of geography, journals and subjects, productive authors and institutions, frequently cited articles, etc. are obtained: articles in this area are mainly distributed in the USA, several countries in Europe and China; the most productive journal, author and institution are Energy Policy, Lund $\mathrm{H}$ from Denmark and National Technical University of Athens in Greece; Energy Fuel is the most popular subject among all the outcomes; the most frequently cited article is written by Demirbas published in Energy Policy in 2007. According to the frequency analysis of keywords, it reveals that: "renewable energy" is a kind of keyword used most frequently; "carbon capture and storage technology" is an emerging keyword which is increasingly concerned about; scholars pay widespread attention to electricity issues, especially the feed-in tariff; the policy mainly includes energy policy and climate policy; the real option theory is the most widely used theory; the existing uncertainty is summarized as the cost uncertainty and policy uncertainty. In the end, several suggestions for the future research are given.
\end{abstract}

Keywords: Low-carbon energy technology; Energy investment; Bibliometric; Frequency analysis

\section{Introduction}

Climate change has been widely discussed in these years and it is agreed that the greenhouse gas emissions are mainly from anthropogenic activities, which needs the whole world to take actions urgently [1]. How to achieve the dual objectives of combating climate change and satisfying the increasing energy demand requires a wide range of measures. The low-carbon

Corresponding author at: University of East Anglia, Norwich NR4 7TJ, UK. Tel: +44 (0) 1603592885.

E-mail address: z.mi@uea.ac.uk (Z.Mi) 
energy technologies are effective means to reach the above goals because they not only reduce the carbon emissions from the energy consumption fundamentally, but also secure the energy supply. At the meantime, many nations have set reduction targets for carbon dioxide emissions to cope with climate change [2-6]. To achieve targets of emissions reduction and the low-carbon energy system, investment in low-carbon energy technologies is essential. Generally, the low-carbon energy technology consists of three types [7]: improving the energy efficiency and conversion rate, such as IGCC power generation; alternative fuels, such as renewable energy, nuclear energy and low-carbon fossil fuels [8-10]; capture and storage greenhouse gases generated from fossil fuel. As a consequence, low-carbon energy technology investment issues are also concentrated on these three aspects, particularly on renewable energy technologies and carbon capture and storage (CCS) [11].

Until now, a large number of publications on low-carbon energy technology investment have emerged [12-17]. Previous studies were reviewed from different perspectives by a handful of scholars. Zeng et al. (2014) explored the status quo of China's renewable energy investment and financing in detail based on the overview of five perspectives: investment situation, investment and financing bodies, investment and financing means, sources of funding and financing channels [18]. Stambouli et al. (2012) provided an analysis of the existing renewable energy sector and a prediction for demand growth, additional capacity and investment requirements [19]. They also discussed the current energy scenario and explored the alternative energy like solar and wind to ensure energy security supply, reliability and higher efficiency in energy conversion, transmission and utilisation. Banos et al. (2011) presented a review of the current state of the art in computational optimization methods applied to renewable and sustainable energy and also presented a vision of the latest research advances in this field [20].

As a tool of quantitative analysis of the literature, the bibliometric method has been widely used to assess the performances of various disciplines [21, 22]. Kiriyama et al. (2013) integrated citation network analysis and bibliometric method to illustrate an overview and trends in nuclear energy technology and related fields [23]. In addition, they also compared the global trends of nuclear energy research and the differences of research conducted in universities and institutes in Japan. Wei et al. (2014) utilized the bibliometric method to summarize the important research topics and methodologies in the field of climate policy modeling based on the dataset of SCI-E and SSCI. In recent years, bibliometric analysis was employed in research of the energy field [24]. Sanz-Casado et al. (2014) conducted a bibliometric analysis of scientific publications on solar energy in Spain and Germany based on Web of Science data. The main conclusion of the work was the divergence in Germany and Spain between solar energy demand/output growth and the growth of research papers on the subject, which was linear [25]. Since China has invested largely in energy-related research and commercialization, through the review of intergovernmental cooperation programs and the bibliometric analysis of the top energy journals, Duan (2011) found that intergovernmental cooperation and non-governmental cooperation were two effective channels for energy R\&D, but for different areas, the degree of cooperation was not the same [26]. Montoya et al. (2014) assessed the contributions of specialized publications from Spanish institutions in the energy field using the Scopus Elsevier database as well as the bibliometric analysis [27]. Kiriyama and Kajikawa offered a bibliometric result on energy security from the perspective of status and trends in the academic publications. It indicated that research focus in energy security has changed from ensuring the self-sufficiency of the primary energy through 
promoting strategies to diversification of the secondary energy supply chain by introducing energy networks including an infrastructure established through international coordination [28]. They analyzed different aspects of the publications, for instance, publication type, field, language, subcategory, journal type, the key word occurrence frequency, international collaboration and the most active categories and concluded that Spanish research was an important and relevant player in the international scientific scene.

It is beneficial and necessary to understand the current research situation, research hotspots and future development trend in the field of low-carbon energy technology investment by sorting out and summarizing the existing literature [20]. However, to the authors' best knowledge that there is no previous work which focuses on trying to solve this issue comprehensively. To make a contribution to filling the gap in the existing studies, we conducted the work from the following aspects. To begin with, the bibliometric method is applied to investigate the latest research status and trend, including the quantity of articles, distributions of geography, journal and subject, productive authors and institutions, academic collation and article citations. In addition, the comprehensive strength between countries is also measured. Second, the frequency analysis of keywords is applied to discover the hottest research topics in this field. Finally, several suggestions regarding of future low-carbon energy technology investment research are given in the conclusion based on the above results.

To sum up, this paper shed light on the current research in the following points: 1) it is the first try to summarize and assess the research trend in the field of low-carbon energy technology investment 2) based on the frequency analysis of keywords, the current hot topics are clarified, which provides scientific reference for the future research 3 ) we conclude the potential research directions according to the summary of the existing literature, which makes a contribution to the future development as well as the research progress of low-carbon energy technology investment.

\section{Materials and Methodology}

The data were collected from databases of Science Citation Index Expanded (SCI-E, 1981-present) and Social Sciences Citation Index (SSCI, 2002-present) compiled by Thomson Reuters. 2121 articles whose topics (titles, keywords and abstracts) contain two types of words, i.e. "low-carbon energy technology" and "investment" were obtained on March 21, 2014. We set the document type and language as "article" and "English", respectively. The results ${ }^{2}$ provided abundant information and the personalized export option were used. Referring to the previous works [21][24][25[27], we selected the following terms to conduct the analysis:

General statistics, such as the quantity of articles, distributions of geography, journal and subject, productive authors and institutions, academic collation, article citations and comprehensive strength. Through the mentioned terms, the latest research status about low-carbon energy technology investment was estimated, which is of benefit to policymakers and researchers who are interested in this field by helping them learn the general situations quickly and provide relevant references on their publications.

Research hotspots. Keywords of one research reflect what the authors are concerned about, so frequency analysis of keywords was used to investigate the research hotspots and trends in the

\footnotetext{
${ }^{2}$ It should be noted that we did not clarify the papers in terms of science and engineering and social science in this
} work. 
field [29] and this method has been applied in quite a few previous studies [30-32]. This paper analyzed the frequency of keywords and summarized hot topics and future trends, which may influence scholars' future study selections.

Next, the methods are clarified to calculate the impact factor, H-index, collaboration degree, comprehensive strength which are used for the following analysis.

\subsection{Impact factor and H-index}

Publication statistics generally characterize authors, institutions, countries, journals etc. and we choose impact factor and H-index to measure their influences.

As one of the most influential tools in modern bibliometrics research [33], Impact Factor (IF) was devised by the Institute for Scientific Information (ISI) and is indexed in the Journal Citation Reports (JCR) yearly. It is defined as:

For any given year, the impact factor of a certain journal is the average number of citations gained by per paper published in that journal during the two preceding years.

In this paper, the impact factor of a given journal is determined as reported in the 2012 Journal Citation Reports.

H-index was first proposed by Hirsch JE in 2005 to measure scientific outputs and it is defined as [34]:

A scientist has index $H$ if $H$ of his/her $N_{p}$ papers have at least $H$ citations each, and the other $N_{p}-H$ papers have no more than $H$ citations each.

where $N_{p}$ is the number of papers published over $n$ years. H-index takes both the quantity and citation of papers into consideration, so it is a useful tool to compare influences of different individuals in a certain field. However, H-index can not only measure the impact of individuals, but also assess the influences of institutions and countries [35]. In our study, H-index is applied to estimate the impacts of countries, institutions and authors through the 2121 articles.

\subsection{Collaboration degree}

In order to study the academic collaboration in the area of low-carbon energy technology investment, three indicators of auctorial, institutional and national collaboration degrees are chosen in our analysis.

$$
\begin{aligned}
& D_{a}=\frac{\sum_{i=1}^{N} \alpha_{i}}{N} \\
& D_{o}=\frac{\sum_{i=1}^{N} \beta_{i}}{N} \\
& D_{c}=\frac{\sum_{i=1}^{N} \gamma_{i}}{N}
\end{aligned}
$$

where $D_{a}, D_{o}, D_{c}$ are auctorial, institutional and national collaboration degrees, 
respectively; $\alpha_{i}, \beta_{i}, \gamma_{i}$ are numbers of authors, institutions and countries for each paper; $N$ is the total number of papers in this field. It should be noted that the numbers of institutions and countries are the sum of all authors' institutions and countries.

\subsection{Comprehensive strength}

The academic ability of one country is reflected in the aspects of academic scale, influence and competence. We choose eight indicators ${ }^{3}$ : total number of articles, total number of citations, number of hot articles, number of hot articles' citations, number of highly cited articles (TOP100), number of highly cited articles' citations (TOP100), number of productive authors and number of productive institutions to assess national comprehensive strength. Standard scores of the eight indicators are obtained using the standard method and then summed to get the total score of one country.

$$
\begin{gathered}
S_{p q}=\frac{x_{p q}-\overline{x_{q}}}{\sqrt{\frac{\sum_{p}\left(x_{p q}-\overline{x_{q}}\right)^{2}}{M}}}+1 \\
S_{p}=\sum_{q} S_{p} .
\end{gathered}
$$

where $S_{p q}$ is the standard score of $q$ indicator in $p$ country; $x_{p q}$ is the original score of $q$ indicator in $p$ country; $\overline{x_{q}}$ is the average score of $q$ indicator; $S_{p}$ is the sum of standard scores in $p$ country; $M$ is the number of countries.

\section{General situation and national comprehensive strength}

\subsection{General statistics}

The 2121 articles are from 103 countries/regions, but they are distributed in a few countries. Fig. 1 illustrates the trends of publications in the top 10 productive countries, of which, China does not include Taiwan region and UK includes England, Scotland, Northern Ireland and Wales.

Within the statistical years of $1985-2013^{4}$, the amount of publications shows an overall upward trend, but it can be clearly divided into two stages: the first stage started from 1985 to 2004 during which it developed stably; the second stage was from 2005 to 2013 in which it developed rapidly, as shown in Fig. 1. The rapid growth trend is consistent with the situation of global investment in renewable energy, which can be found in Fig. 1 that it experienced a fast increase especially from 2004 to 2011. As estimated by Bloomberg New Energy Finance, the global new investment in renewable power and fuels was 270 billion USD in 2014 from only 45 billion USD in 2004. At the former stage, the number of documents grew slowly, only accounting for $13.15 \%$ of the total number; at the later stage, a fast growth was witnessed at annual growth

\footnotetext{
3 Hot articles are TOP20 highly cited articles published during 2012 and 2013; Productive authors are those who have published 4 or more articles, amounting to 78 and we count the countries of their first institution; Productive institutions are those which have published 7 or more articles, 98 totally.

4 The first paper in this field was published in 1985. We only show the result from 1985 to 2013, because papers in 2014 have not completely included in the dataset,
} 
rate of $29.06 \%$, of which the number of publications in 2013 was equivalent to 1.5 times of that in the first phase. The number still keeps increasing now, indicating that this field has entered a stage of rapid development.

$* * * * * * * * * * * * * * * *$

Insert Fig. 1 here

$* * * * * * * * * * * * * * * *$

\subsection{Number of publications by countries}

Table 1 shows the situations of publications and $\mathrm{H}$-index of the top 15 productive countries and Fig. 2 illustrates the geographical distribution of the total publications of the top 50 productive countries.

$* * * * * * * * * * * * * * * * * * *$

Insert Table 1 here

$* * * * * * * * * * * * * * * * * * *$

$* * * * * * * * * * * * * * * *$

Insert Fig. 2 here

$* * * * * * * * * * * * * * * *$

Publications in this area are mainly distributed in the USA, China and several countries of Europe, such as UK, Germany, Italy, etc. USA was the first country to start the research and three of the four earliest papers [36-39] were from the USA (Fig. 1), laying its position in this field. As for 2013, the number of articles from the USA accounted for $22.25 \%$ of the world's total amount, far more than those of any other countries. Following USA, UK ranks the second in the number of documents. The reason for this kind of distribution seems obvious: the Europe has always been the most positive advocator for carbon emissions reduction; USA and China are two biggest carbon emitters in the world now, so both of them are facing great pressure of carbon emissions reduction. Among the top 10 productive countries, eight are developed countries which have more advantages than the developing countries. However, the research process is a bit far behind from the actual situation of investment. Again, take renewable energy investment as an example, the top 10 national investors in renewable energy consisted of four developing countries and six developed countries in 2014. As also can be seen from Fig. 1, the difference between investments in developing countries and developed countries is shrinking, with the proportion representing the world total ranging from $60.0 \%$ in 2004 to $16.4 \%$ in 2013 .

As the only developing country, the first article published in China in the field was in 1988, but until in 2007, it started to increase speedily. Although it has a late start, the total number of articles from China ranks the fourth. Furthermore, it showed a rapid growth in recent years and the average annual growth rate during $2005-2013$ is $38.17 \%$, higher than the world's overall growth rate. In the "Bali Road Map" adopted in 2007, China and other developing countries promised to 
undertake the corresponding responsibility to address climate change, thus giving birth to a large number of China's scientific outputs in low-carbon energy technology investment.

However, apart from the above reasons, the whole research strength of each country also contributes to the current publications distribution. In other words, to some extent, the publications distribution in this area reflects the general situation of different countries in the scientific community. The total publications of all research areas from datasets of SCI-E (1981-present) and SSCI (2002-present) are also shown in Table 1. It is obvious that USA and UK still have far more publications than others, especially USA. In addition, in other energy- or environment-related works, such as climate policy modeling research [24], carbon market research [21], etc., it shows the similar trend as well, with USA and UK as the leading countries.

\subsection{Journal distribution}

For the journal sources, the literature in this field is from 495 journals, Table 2 displays the top 15 productive journals and Fig. 3 shows their growth trends of publications over time. The journal distribution is concentrative, similar to the situation of the national distribution. The amount of articles in the listed 10 journals accounts for nearly $50 \%$ of the total and continues to rise, of which the number of Energy Policy is the most, representing 20\% or so. Moreover, amounts of articles from the two journals of Renewable Energy and Energy grew rapidly over the past five years.

However, as for the citations per publication, the three journals above are inferior to journals of Biomass Bioenergy, International Journal of Hydrogen Energy, Solar Energy, International Journal of Greenhouse Gas Control, Journal of Cleaner Production and Energy Conversion and Management. According to the results of Web of Science, all of the journals in the list do not have open access. If the journals have more specific subjects and the subjects also match the research hotspots (Section 4) in this area, such as journals of Biomass Bioenergy, International Journal of Hydrogen Energy and Solar Energy, they receive more citations per publication. As for journals of International Journal of Greenhouse Gas Control and Journal of Cleaner Production, their subjects fit in with the theme of "low-carbon" of this area, so they also have higher citation-per-publication.

$* * * * * * * * * * * * * * * * * * *$

Insert Table 2 here

$* * * * * * * * * * * * * * * * * * *$

$* * * * * * * * * * * * * * * *$

Insert Fig. 3 here

$* * * * * * * * * * * * * * * *$

\subsection{Subject distribution}

The contribution of the top 15 subjects in the field of low-carbon energy technology investment is listed in Table 3. 
$* * * * * * * * * * * * * * * * * * *$

Insert Table 3 here

$* * * * * * * * * * * * * * * * * * *$

Energy Fuel is the most popular subject with 1224 records, accounting for $57.52 \%$ of the total number, followed by Environmental Sciences Ecology and Engineering, with 33.04\% and $24.34 \%$ of the total records, respectively. The category description for Energy Fuels is "Energy Fuels covers resources on the development, production, use, application, conversion, and management of nonrenewable (combustible) fuels (such as wood, coal, petroleum, and gas) and renewable energy sources (solar, wind, biomass, geothermal, hydroelectric)." Along with the severe situation of climate change, renewable energy is chosen to take the responsibility of reducing carbon dioxide and many nations have set the targets for renewable energy development, including the USA, UK, China, etc. Thus, in terms of low-carbon energy technology investment, more than half of the studies belong to the subject of Energy Fuels, involving renewable energy study. From Fig. 4, more than half (55.7\%) of the publications are from the SCI-E dataset which includes over 8500 of the world's scientific and technical journals across 150 discipline and only $11.8 \%$ of the results are from SSCI dataset which includes 3000 of the world's social sciences journals across disciplines. On the one hand, it may be as a result of the scales of the two kinds of datasets. More importantly, it indicates that articles in the concerned research area pay close attention to the technical or scientific aspects. However, there are still $32.6 \%$ of the results from both of the SCI-E and SSCI datasets, which reveals that this scientific problem is a highly multidisciplinary one.

$* * * * * * * * * * * * * * * *$

Insert Fig. 4 here

$* * * * * * * * * * * * * * * *$

\subsection{Author statistics}

According to the results, 2121 publications were produced by 5054 authors. Among them, 37 authors have five or more publications in this field, with the proportion of $1.74 \%$ representing the total authors and their publications account for $11.22 \%$ of the total amount. Table 4 lists the top 15 productive authors, of which, four come from Austria, ranking the first and two are from Denmark and Sweden, respectively. The productive authors are mostly from European countries.

The most productive author is Lund H from Denmark, with 13 records. Demirbas A from Turkey receives the most citations per publication, with 52.75. Lund $\mathrm{H}$ is one of the 250 Thomson Reuters Highly Cited Researchers within engineering in the world, who focuses on Energy System Analysis, Public Regulation and Technological Change in Energy Sector, etc. Among his 13 articles in this area, three of them are cited more than 100 times [40-42]. In the three highly-cited papers, he (and the co-authors) investigated the roles of different kinds of renewable energies, such as PV, wind and wave power or new energy technology, i.e. compressed air energy storage 
(CAES) in different future energy systems, including electricity sector. The highest cited article from Demirbas A studied the importance of biodiesel as transportation fuel, from the perspectives of advantages and disadvantages of biodiesel as diesel fuel, biodiesel economy and biodiesel policy [43].

$* * * * * * * * * * * * * * * * * * *$

Insert Table 4 here

$* * * * * * * * * * * * * * * * * * *$

\subsection{Institution statistics}

The result reveals that 2121 publications distribute in 1803 research institutions. Table 5 lists the top 15 productive institutions, of which three are in USA and UK, and two are in China and Greece. Most of the 15 institutions are from developed countries, with only Chinese Academy of Sciences and Tsinghua University coming from the developing country. Meantime, except the Chinese Academy of Sciences and the International Institute for Applied Systems Analysis, others are all universities. Therefore, developed countries are in the lead, compared with developing countries, and the university is the critical research effort.

$* * * * * * * * * * * * * * * * * * *$

Insert Table 5 here

$* * * * * * * * * * * * * * * * * * *$

\subsection{Academic collaboration}

According to the equations (1) (2) and (3) in Section 2.2, three levels of collaboration degrees are drawn, as shown in Fig. 5. The auctorial collaboration degree increases apparently, up to 3.34. In contrast, institutional and national collaboration degrees are steady and relatively low, especially the national collaboration degree, because issues in one particular country are more concerned about in this field. The three average degrees are 2.29, 1.41 and 1.14, respectively, that is, 2.29 authors, 1.41 institutions and 1.14 countries participated in one article averagely. However, for different areas, the degree of collaboration is not the same as Duan (2011) indicated [26].

$* * * * * * * * * * * * * * * *$

Insert Fig.5 here

$* * * * * * * * * * * * * * * *$

\subsection{Article citation}

The citation frequency of one publication reflects its academic influence. Table 6 lists the top 15 frequently cited articles. The most frequently cited article was published in 2007 in Energy Policy, written by Demirbas from Turkey. Until when we searched, it has been cited for 223 times 
with average citations per year of 31.56 and it was briefly introduced in Section 3.4. Among the top 15 frequently cited articles, four are from USA. Thus, from the perspective of influence, USA again has strong strength.

$* * * * * * * * * * * * * * * * * * *$

Insert Table 6 here

************************

\subsection{National comprehensive strength in the field of low-carbon energy technology investment}

According to equations (4) and (5), we calculate the national ranking of comprehensive scores in the field of low-carbon energy technology investment, as shown in Fig. 6. The overall strength of USA is still far ahead, with total standard score of 32.99. UK ranks the second, with 13.73. Although the total number of articles in Denmark is not dominant, the numbers of productive authors and most cited papers are large, making it rank the third. Among the top 15 countries, only China and Turkey are developing countries, ranking the fourth and eighth, respectively, others are all developed countries.

$* * * * * * * * * * * * * * * *$

Insert Fig.6 here

*******************

\section{Research hotspots}

On the basis of frequency analysis of keywords, Table 7 lists the frequently used keywords in this field during 1991-2013.

$* * * * * * * * * * * * * * * * * * *$

Insert Table 7 here

$* * * * * * * * * * * * * * * * * * * *$

By summarizing the keywords in Table 7, the research hotspots are drawn as follows: renewable energy, carbon capture and storage, electricity, policy, real options theory and uncertainty.

(1) Renewable energy

As can be seen from Table 7, "renewable energy" is one kind of keyword which is used most frequently, far more than other keywords, of which wind [57], biomass [58] and solar [59] are the most concerned about. In addition, the frequency keeps increasing quickly.

(2) Carbon capture and storage

Although "carbon capture and storage" is an emerging keyword, the upward trend is quite 
rapid, with the frequency increasing from six times during 2004-2008 to 52 times during 2009-2013, indicating that it may be the future research focus. This trend is highly influenced by the development of shale gas industry in recent years. Shale gas can guarantee energy security and emit less carbon dioxide than coal. But in the long run, shale gas would only fit into future energy system if it's possible to implement CCS to capture the carbon emissions from it [60]. Therefore, the research for CCS is of great significance.

Scholars pay attention to the cost-effectiveness and existing risks of carbon capture and storage technology investments [61] as well as the impact on the future development of the energy system [62].

\section{(3) Electricity}

The keyword of "electricity" appears frequently and scholars focus on what impact the introduction of low-carbon energy technology will have on the power system or the electricity market. In particular, "feed-in tariff" is the keyword with highest frequency in the "electricity" issues and it can be seen from Table 7 that it has been paid increasing attention over the last five years.

\section{(4) Policy}

The development of low-carbon energy technology needs to take the policy into consideration. In this field, the relevant policies mainly include energy policy [63] and climate policy [64], of which, energy policy basically refers to renewable energy policy.

\section{(5) Real option theory}

The real option theory is the most widely used theory in the field of low-carbon energy technology investment $[59,65]$. Due to the uncertainty of future profits, the sinking of investment costs and the flexibility of project implementation of low-carbon energy technology, the real option theory is a more appropriate solution to solve this issue.

\section{(6) Uncertainty}

In this area, a wide range of uncertainties exists, but they can be divided into cost uncertainty and policy uncertainty $[66,67]$, of which, the cost uncertainty includes the uncertainty of carbon price, electricity price, investment cost, additional O\&M cost [61] and so on. The policy uncertainty consists of energy policy uncertainty and climate policy uncertainty [64].

Apart from the above hot topics, "China" is the only region among the top 20 most frequently used keywords. From this point of view, researchers are highly concerned about China's low-carbon energy investment problems. Actually, China was in the lead in terms of investment in renewable energy in 2014, accounting for nearly one third of global total. Furthermore, China accounted for $63 \%$ of developing country investment in 2014, up from 61\% in 2013 [68]. However, in the future research, it is promising to identify what kinds of topics researchers are focused on in different regions. 


\section{Concluding remarks and future work}

According to the bibliometric analysis of low-carbon energy technology investment, the following conclusions are drawn:

(1) This field of low-carbon energy technology investment has entered a stage of rapid development with the number of publications increasing at the growth rate of $29.06 \%$ since 2005 and the number still keeps increasing now; publications are mainly centered in USA, several countries in Europe and China; the strength of the developed countries is far greater than that of developing countries in terms of the total number of articles, productive authors and productive institutions; among the top 15 countries, only China and Turkey are developing countries, while the others are developed countries; the comprehensive strength of USA ranks the first in the field, reflected in the total number of articles, productive institutions and highly-cited papers and then it is followed by UK and Denmark; the auctorial collaboration degree shows a clear upward trend while institutional and national collaboration degrees are steady and relatively low, with average degrees of $2.36,1.44$ and 1.15 , respectively.

(2) In this field, the most productive journal is Energy Policy, whose records account for $20 \%$ of the total amount; Energy Fuels is the most popular subject, with records of 1224, representing $57.22 \%$; the most productive author is Lund H from Denmark who has published 13 articles; the most productive institution is National Technical University of Athens with 28 publications; the article which receives the most citations is from Demirbas A in Turkey, published in Energy Policy in 2007 and until the research time, it has been cited for 223 times.

(3) According to the analysis of keyword frequency, it reveals that: "renewable energy" is one kind of keyword used most frequently, of which, wind, biomass and solar are the most concerned about; "carbon capture and storage" is an emerging keyword and is paid increasing attention; scholars have great interest in electricity issues, especially the feed-in tariff; the policy mainly includes energy policy and climate policy; the real option theory is the most widely used theory; the existing uncertainty can be summarized as the cost uncertainty and policy uncertainty.

Despite of the rapid development, this area is still at the early stage and several suggestions for the future research are concluded as follows.

(1) Compared with the traditional energy, whether the low-carbon energy technologies have investment advantages

In the context of climate change, low-carbon energy can effectively reduce carbon dioxide emissions from the energy supply side and guarantee energy security to a certain extent. However, the substitute relation exists between low-carbon energy and traditional fossil fuels (coal, oil, etc.). In consideration of the uncertainties of carbon prices, energy prices, electricity prices and policy, whether the low-carbon energy has investment advantages compared with traditional fossil fuels for investors needs careful considerations. Therefore, it is worthwhile to evaluate and compare the emission reductions potential and investment potential of low-carbon energy technologies. In addition, unlike fossil energy technologies, low-carbon energy technologies are at the immature stage, making the cost high. In order to facilitate the development and enhance the competitive advantages, efforts should be made in terms of policy making, market structure, pricing mechanism, etc.

(2) Taking into account the effective and reasonable allocation of investment, how will the future electricity generation mix change? 
The main application of low-carbon energy technologies is in the electricity sector. However, in the global electricity production system, renewable energy generation still represents a small proportion, with the percentage of $22.1 \%$ making up the total amount in 2013, while fossil fuels and nuclear power accounted for $77.9 \%$. With the economic development, energy security situation is increasingly serious, which puts forward higher requirements for the power system. Therefore, the questions is raised: to ensure the rational and efficient allocation of investment and meet the requirements of energy security and climate change mitigation, how will the global generation mix or a particular regional generation mix change in the future, that is, what role of low-carbon energy generation will play in future power supply systems?

(3) The research methods need to be more innovative and the financial theory is encouraged to be combined with management science methods

Existing studies mostly use financial theory to solve the problems, but low-carbon energy technology investment is one of the complex scientific issues with systematicness, comprehensiveness and uncertainty. Also it is a multidisciplinary problem. Thus, simply applying finance theory cannot solve the problem properly and it needs to combine the interdisciplinary theories, especially the management science methods (such as operations research theory, etc.). The low-carbon energy technology investment issue can be processed into strategic investment issue, considering not only the uncertainties and investment incomes faced in the process of investment, but also the strategy from the macro level.

This study is the first attempt to overview the latest research status and the most interesting topics and to propose suggestions for the future research in the field of low-carbon energy technology investment. The results are useful for the real application, which not only benefit scholars in this area, but also advantage investors to make decisions in low-carbon energy technologies. From the perspective of researchers, since we summarized the research situation, such as the productive journals, productive authors, highly cited papers and research hotspots, then they have more specific targets when carrying out the relevant research. For example, because we provided the highly cited papers in this area, according to which, it may give researchers some valuable ideas. In addition, researchers may also pay close attention to works of the most productive authors. Furthermore, we also pointed the commonly used research methods and concluded that in the future the research methods need to be more innovative and comprehensive, which is an useful reference for the researchers. From the perspective of investors, on the basis of frequency analysis of keywords, they not only can identify the potential investment objectives, also need to be careful of the uncertainties and the important influence factors, such as the energy policy, when making real investment.

However, it still includes several limitations remained to be solved in the future work: (1) Because of the complexity of authors' and institutions' names, the total publication maybe not calculated accurately enough. Meanwhile, countries such as UK include several parts, so the total amount may be repeatedly counted. (2) As the database updates, the results, such as the citations, the total publications, etc. will change, so the results are not the latest (3) Apart from the bibliometric analysis, it is necessary to do more detailed literature reviews by figuring out the most related articles to explore the most interesting research questions and the most frequently used methodologies in this area. 


\section{Acknowledgements}

The authors gratefully acknowledge the financial support from the "Strategic Priority Research Program" of the Chinese Academy of Sciences (XDA05150600), and National Natural Science Foundation of China (71020107026). We appreciate the comments from the seminar participants at Center for Energy \& Environmental Policy Research at Beijing Institute of Technology which makes the manuscript improve greatly.

\section{References}

[1] Yu, H., Wang, B., Zhang, Y.-J., Wang, S., Wei, Y.-M., 2013. Public perception of climate change in China: results from the questionnaire survey. Nat Hazards 69, 459-472.

[2] CCC, 2008. Building a Low-carbon Economy-the UK's contribution to tacking climate change. Committee on Climate change, London.

[3] Scottish Government, 2011. Low carbon Scotland: Meeting the emissions reduction targets 2010-2022: The report on proposals and policies Scottish government. Edinburgh.

[4] Mi, Z.-F., Pan, S.-Y., Yu, H., Wei, Y.-M., 2015. Potential impacts of industrial structure on energy consumption and $\mathrm{CO}_{2}$ emission: a case study of Beijing. J. Clean. Prod. 103, 455-462.

[5] Cong, R.-G., Wei Y.-M., 2010. Potential impact of (CET) carbon emissions trading on China's power sector: A perspective from different allowance allocation options. Energy 35(9), 3921-3931.

[6] Cong, R.-G., Wei Y.-M., 2012. Experimental comparison of impact of auction format on carbon allowance market. Renew. Sust. Energ. Rev. 16(6), 4148-4156.

[7] Wei, Y.-M., Liu, L.C., Fan, Y., Wu, G., 2008. China Energy Report (2008): $\mathrm{CO}_{2}$ Emissions Research. Science Press, Beijing.

[8] Cong, R.-G., 2013. An optimization model for renewable energy generation and its application in China: a perspective of maximum utilization. Renew. Sust. Energ. Rev. 17, 94-103.

[9] Cong, R.-G., Shen S., 2014. How to develop renewable power in China? A cost-effective perspective. The Scientific World Journal 2014.

[10] Yu, H., Pan, S.-Y., Tang, B.-J., Mi, Z.-F., Zhang, Y., Wei, Y.-M., 2015. Urban energy consumption and $\mathrm{CO}_{2}$ emissions in Beijing: current and future. Energ. Effic. 8, 527-543.

[11] Hoffmann, B.S., Szklo, A., 2011. Integrated gasification combined cycle and carbon capture: A risky option to mitigate $\mathrm{CO}_{2}$ emissions of coal-fired power plants. Appl. Energy 88, 3917-3929.

[12] Detert, N., Kotani, K., 2013. Real options approach to renewable energy investments in Mongolia. Energy Policy 56, 136-150.

[13] Baringo, L., Conejo, A.J., 2013. Correlated wind-power production and electric load scenarios for investment decisions. Appl. Energy 101, 475-482.

[14] Behrens, P., Rodrigues, J.F.D., Brás, T., Silva, C., 2016. Environmental, economic, and social impacts of feed-in tariffs: A Portuguese perspective 2000-2010. Appl. Energy 173, 309-319.

[15] Vogele, S., Rubbelke, D., 2013. Decisions on investments in photovoltaics and carbon capture 
and storage: A comparison between two different greenhouse gas control strategies. Energy $62,385-392$.

[16] Zhou, W.J., Zhu, B., Fuss, S., Szolgayova, J., Obersteiner, M., Fei, W.Y., 2010. Uncertainty modeling of CCS investment strategy in China's power sector. Appl. Energy 87(7), 2392-2400.

[17] Baringo, L., Conejo, A.J., 2011. Wind power investment within a market environment. Appl. Energy 88, 3239-3247.

[18] Zeng, M., Liu, X., Li, Y., Peng, L., 2014. Review of renewable energy investment and financing in China: Status, mode, issues and countermeasures. Renew. Sust. Energ. Rev. 31, 23-37.

[19] Stambouli, A.B., Khiat, Z., Flazi, S., Kitamura, Y., 2012. A review on the renewable energy development in Algeria: Current perspective, energy scenario and sustainability issues. Renew. Sust. Energ. Rev. 16 (7), 4445-4460.

[20] Banos, R., Manzano-Agugliaro, F., Montoya, F.G., Gil, C., Alcayde, A., Gomez, J., 2011. Optimization methods applied to renewable and sustainable energy: A review. Renew. Sust. Energ. Rev. 15 (4), 1753-1766.

[21] Du, H., Li, B., Brown, M.A., Mao, G., Rameezdeen, R., Chen, H., 2015. Expanding and shifting trends in carbon market research: a quantitative bibliometric study. J. Clean. Prod. 103, 104-111.

[22] Ignacio, C.-G., Fernando, R.M., Cruz, C.-P., Ana, P.-M., 2014. Bibliometric analysis in the international context of the "Construction and Building Technology" category from the Web of Science database. Constr. Build. Mater. 53, 13-25.

[23] Kiriyama, K., Kajikawa, Y., Fujita, K., Iwata, S., 2013. A lead for transvaluation of global nuclear energy research and funded projects in Japan. Appl. Energy 109, 145-153.

[24] Wei, Y.-M., Mi, Z.-F., Huang Z., 2014. Climate policy modeling: An online SCI-E and SSCI based literature review. Omega 57, 70-84.

[25] Sanz-Casado, E., Lascurain-Sánchez, K.L., Serrano-Lopez, A.E., Larsen, B., Ingwersen, P., 2014. Production, consumption and research on solar energy: The Spanish and German case. Renew. Energ. 68, 733-744.

[26] Duan, L., 2011. Analysis of the relationship between international cooperation and scientific publications in energy R\&D in China. Appl. Energy 88, 4229-4238.

[27] Montoya, F.G., Montoya, M.G., Gómez, J., Manzano-Agugliaro, A., Alameda-Hernández, E., 2014. The research on energy in spain: A scientometric approach. Renew. Sust. Energ. Rev. 29, 173-183.

[28] Kiriyama, E., Kajikawa, Y., 2014. A multilayered analysis of energy security research and the energy supply process. Appl. Energy 123, 415-423.

[29] Wang, Q., Yang, Z., Yang, Y., Long, C., Li, H., 2014. A bibliometric analysis of research on the risk of engineering nanomaterials during 1999-2012. Sci. Total. Environ. 473-474, 483-489.

[30] Chiu, W.T., Ho, Y.S., 2007. Bibliometric analysis of tsunami research. Scientometrics 73(1), 3-17.

[31] Xie, S.D., Zhang, J., Ho, Y.S., 2008. Assessment of world aerosol research trends by bibliometric analysis. Scientometrics 77(1), 113-130.

[32] Li, L.L., Ding, G.H., Feng, N., Wang, M.H., Ho, Y.S., 2009. Global stem cell research trend: 
bibliometric analysis as a tool for mapping of trends from 1991 to 2006. Scientometrics 80(1), $39-58$.

[33] Du, H., Li, N., Brown, M.A., Peng, Y., Shuai, Y., 2014. A bibliographic analysis of recent solar energy literatures: The expansion and evolution of a research field. Renew. Energ. 66, 696-706.

[34] Hirsch, J.E., 2005. An index to quantify an individual's scientific research output. Proc. Natl. Acad. Sci. 102 (46), 16569-16572.

[35] Kinney, A.L., 2007. National scientific facilities and their science impact on nonbiomedical research. Proc. Natl. Acad. Sci. 104 (46), 17943-17947.

[36] Fung, T.K., Holte, K.C., 1985. Investment value analysis for renewable energy projects. IEEE T. Power Ap. Syst. 104(3), 531-537.

[37] Hassler, C.C., Jones, K.D., 1989. Impact of the 1986 Tax Reform Act on investments in wood biomass energy systems. Biomass 20(3-4), 229-236.

[38] Harrison, S.L., Cooper, D.F., Chapman, C.B., 1988. Hydropower at Canford-A case study in investment appraisal. J. Oper. Res. Soc. 39(5), 447-451.

[39] Ashenayi, K., Ramakumar, R., 1990. IRES-A program to design integrated renewable energy systems. Energy 15(12), 1143-1152.

[40] Lund, H., 2006. Large-scale integration of optimal combinations of PV, wind and wave power into the electricity supply. Renew. Energ. 31(4), 503-515.

[41] Lund, H., Salgi, G., 2009. The role of compressed air energy storage (CAES) in future sustainable energy systems. Energ. Convers. Manage. 50(5), 1172-1179.

[42] Lund, H., 2005. Large-scale integration of wind power into different energy systems. Energy 30(13), 2402-2412.

[43] Demirbas, A., 2007. Importance of biodiesel as transportation fuel. Energy Policy 35(9), 4661-4670.

[44] Hamelinck, C.N., Faaij, A.P.C., 2002. Future prospects for production of methanol and hydrogen from biomass. J. Power Sources 111(1), 1-22.

[45] Brabec, C.J., Hauch, J.A., Schilinsky, P., Waldauf, C., 2005. Production aspects of organic photovoltaics and their impact on the commercialization of devices. MRS Bull. 30(1): 50-52.

[46] Nepstad, D.C., Stickler, C.M., Soares, B., Merry, F., 2008. Interactions among Amazon land use, forests and climate: prospects for a near-term forest tipping point. Philos. T. Ro. Soc. B. 363(1498), 1737-1746.

[47] Caputo, A.C., Palumbo, M., Pelagagge, P.M., Scacchia, F., 2005. Economics of biomass energy utilization in combustion and gasification plants: effects of logistic variables. Biomass Bioenergy 28(1), 35-51.

[48] Burney, J.A., Davis, S.J., Lobell, D.B., 2010. Greenhouse gas mitigation by agricultural intensification. Proc. Natl. Acad. Sci. 107(26), 12052-12057.

[49] Demirbas, A., 2001. Energy balance, energy sources, energy policy, future developments and energy investments in Turkey. Energ. Convers. Manage. 42(10), 1239-1258.

[50] Enriquez, S., Mendez, E.R., Iglesias-Prieto, R., 2005. Multiple scattering on coral skeletons enhances light absorption by symbiotic algae. Limnol. Oceanogr. 50(4), 1025-1032.

[51] Bhowmik, S., Spee, R., Enslin, J.H.R., 1999. Performance optimization for doubly fed wind power generation systems. IEEE T. Ind. Appl. 35(4), 949-958.

[52] Hammerschlag, R., 2006. Ethanol's energy return on investment: A survey of the literature 
1990- Present. Environ. Sci. Technol. 40(6), 1744-1750.

[53] de Vries, B.J.M., van Vuuren, D.P., Hoogwijk, M.M., 2007. Renewable energy sources: Their global potential for the first-half of the 21st century at a global level: An integrated approach. Energy Policy 35(4), 2590-2610.

[54] Junginger, M., Faaij, A., Turkenburg, W.C., 2005. Global experience curves for wind farms. Energy Policy 33(2), 133-150.

[55] Bresesti, P., Kling, W.L., Hendriks, R.L., Vailati, R., 2007. HVDC connection of offshore wind farms to the transmission system. IEEE T. Energy Conver. 22(1), 37-43.

[56] Foxon, T.J., Gross, R., Chase, A., Howes, J., Arnall, A., Anderson, D., 2005. UK innovation systems for new and renewable energy technologies: drivers, barriers and systems failures. Energy Policy 33(16), 2123-2137.

[57] Gillenwater, M., Lu, X., Fischlein, M., 2014. Additionality of wind energy investments in the U.S. voluntary green power market. Renew. Energ. 63, 452-457.

[58] Daigneault, A., Sohngen, B., Sedjo, R., 2012. Economic approach to assess the forest carbon implications of biomass energy. Environ. Sci. Technol. 46(11), 5664-5671.

[59] Martinez-Cesena, E.A., Azzopardi, B., Mutale, J., 2013. Assessment of domestic photovoltaic systems based on real options theory. Prog. Photovoltaics 21(2), 250-262.

http://www.carbonbrief.org/blog/2012/05/lord-smith-comments-on-shale-gas-emissions/ [Accessed on July 23, 2015].

[61] Zhang, X., Wang, X.W., Chen, J.J., Xie, X., Wang. K., Wei, Y.M., 2014. A novel modeling based real option approach for CCS investment evaluation under multiple uncertainties. Appl. Energy 113, 1059-1067.

[62] Lund, H., Mathiesen, B.V., 2012. The role of Carbon Capture and Storage in a future sustainable energy system. Energy 44(1), 469-476.

[63] Winkler, H., 2005. Renewable energy policy in South Africa: policy options for renewable electricity. Energy Policy 33(1), 27-38.

[64] Yang, M., Blyth, W., Bradley, R., Bunn, D., Clarke, C., Wilson, T., 2008. Evaluating the power investment options with uncertainty in climate policy. Energ. Econ. 30(4), 1933-1950.

[65] Lee, S.C., Shih, L.H., 2010. Renewable energy policy evaluation using real option model-The case of Taiwan. Energ. Econ. 32 (S1), S67-S78.

[66] von Stechow, C., Watson, J., Praetorius, B., 2011. Policy incentives for carbon capture and storage technologies in Europe: A qualitative multi-criteria analysis. Global. Environ. Chang. 21(2), 346-357.

[67] Nelson, T., Nelson, J., Ariyaratnam, J., Camroux, S., 2013. An analysis of Australia's large scale renewable energy target: Restoring market confidence. Energy Policy 62, 386-400.

[68] REN 21, 2015. Renewables 2015-Global status report. http://www.ren21.net/GSR-2015-Report-Full-report-EN-Lite [27 May, 2016]. 


\section{List of Figure Captions:}

Fig.1. Timeline of publications in top 10 productive countries, 1985-2013

Fig.2. Geographical distributions of publications, 1985-2014

Fig.3. Timeline of publications in the top 10 productive journals, 1985-2013

Fig.4. SCI-E and SSCI distribution of publications, 1985-2014

Fig.5. Three levels of collaboration degrees, 1985-2013

Fig.6. The national comprehensive strength, 1985-2014 


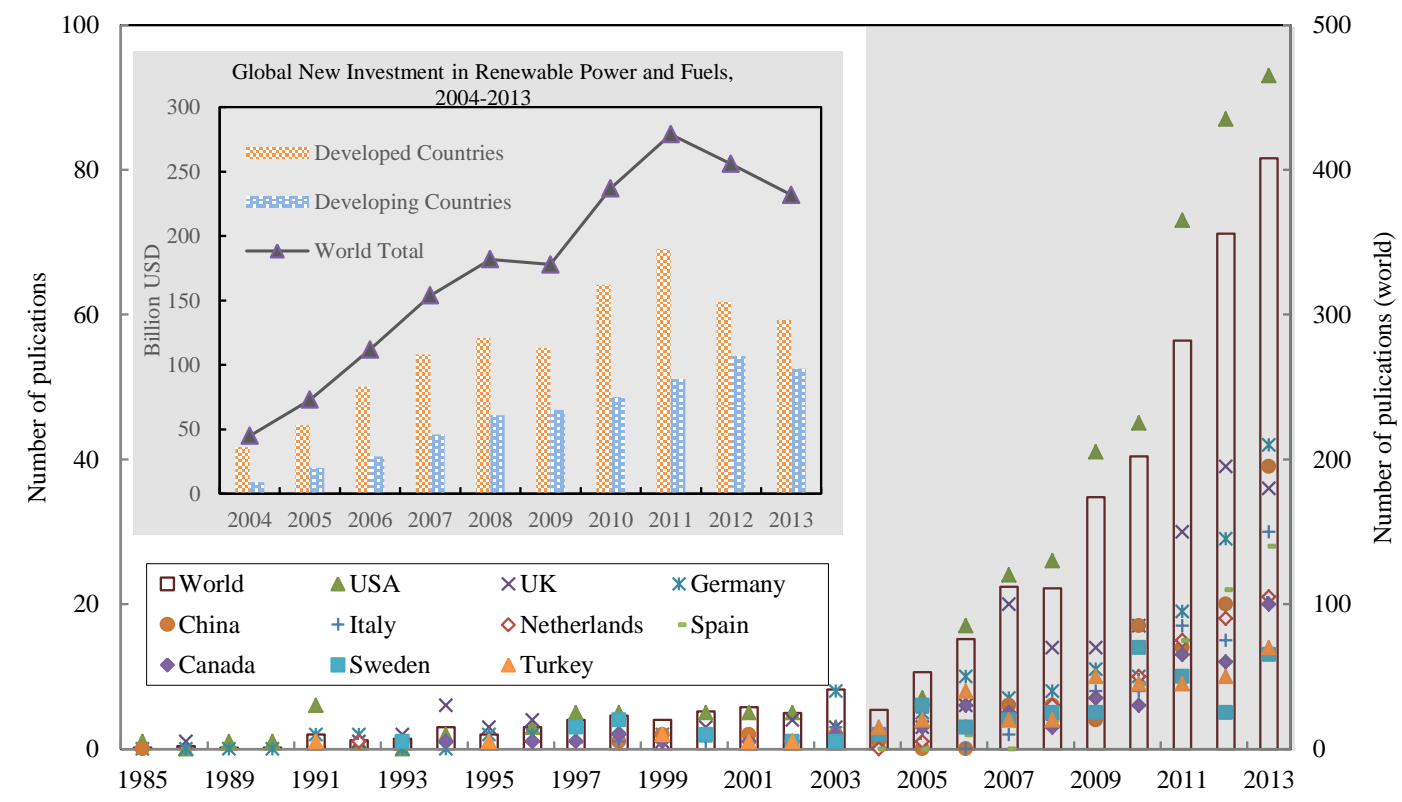

Source: REN (2015) and the authors' calculation.

Fig.1. Timeline of publications in top 10 productive countries, 1985-2013 


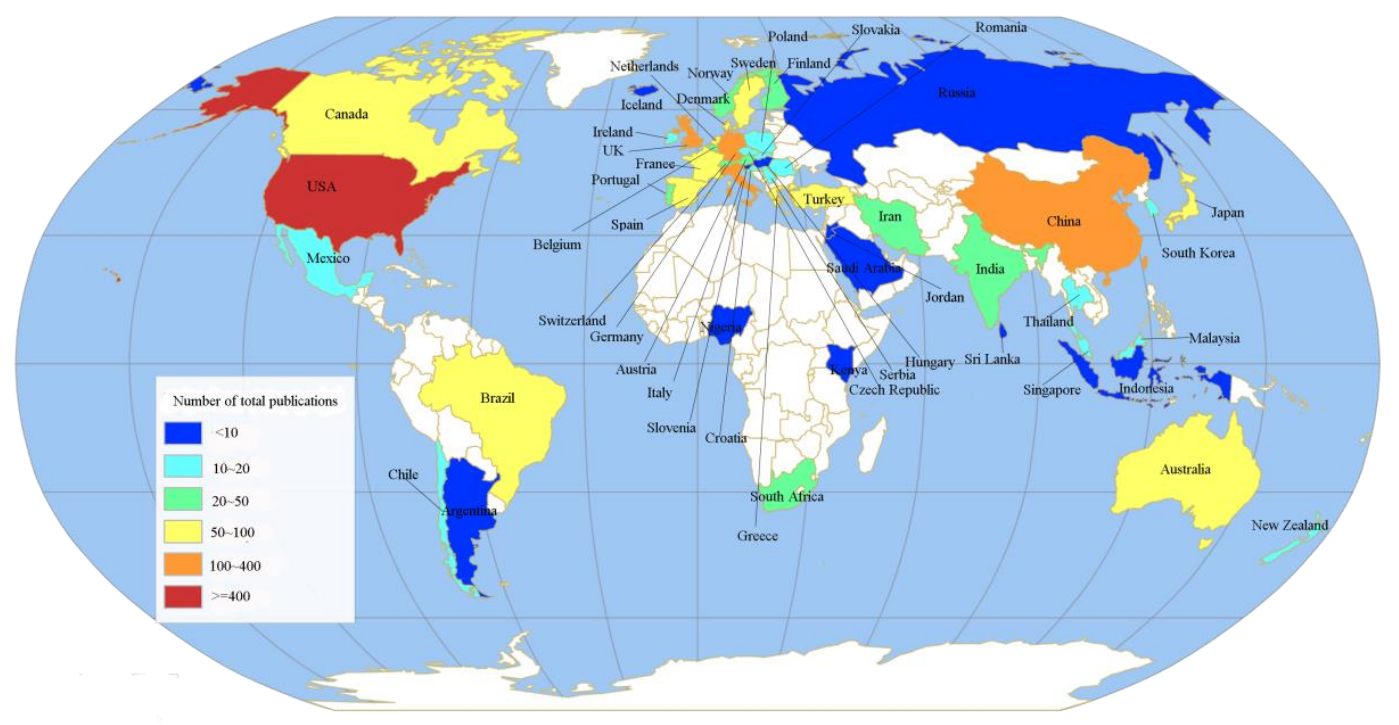

Fig.2. Geographical distributions of publications, 1985-2014 


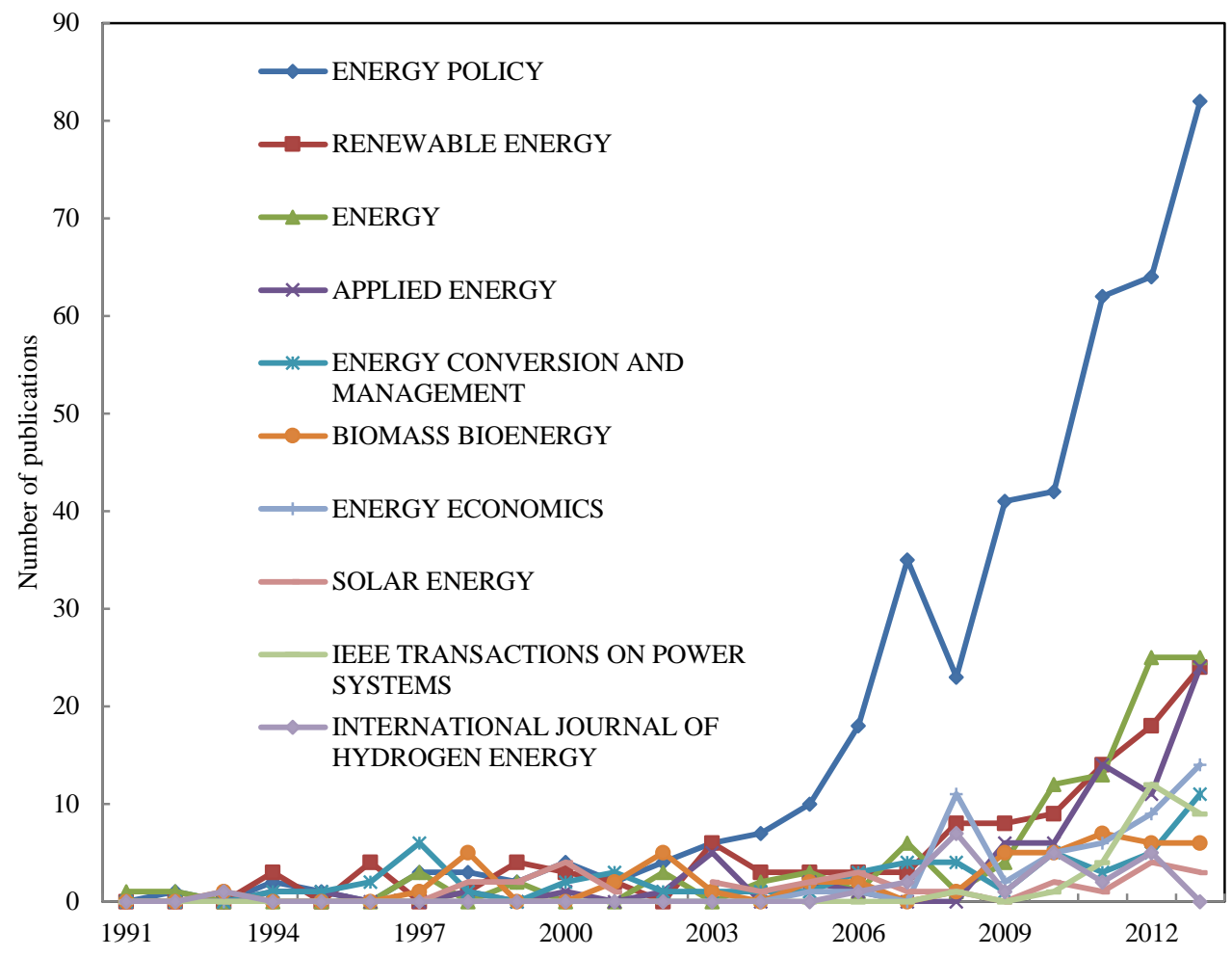

Fig.3. Timeline of publications in the top 10 productive journals, 1985-2013 


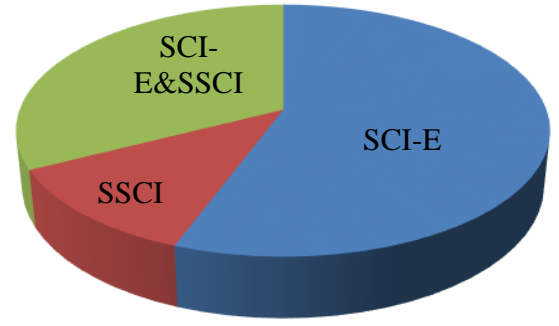

Fig.4. SCI-E and SSCI distribution of publications, 1985-2014 


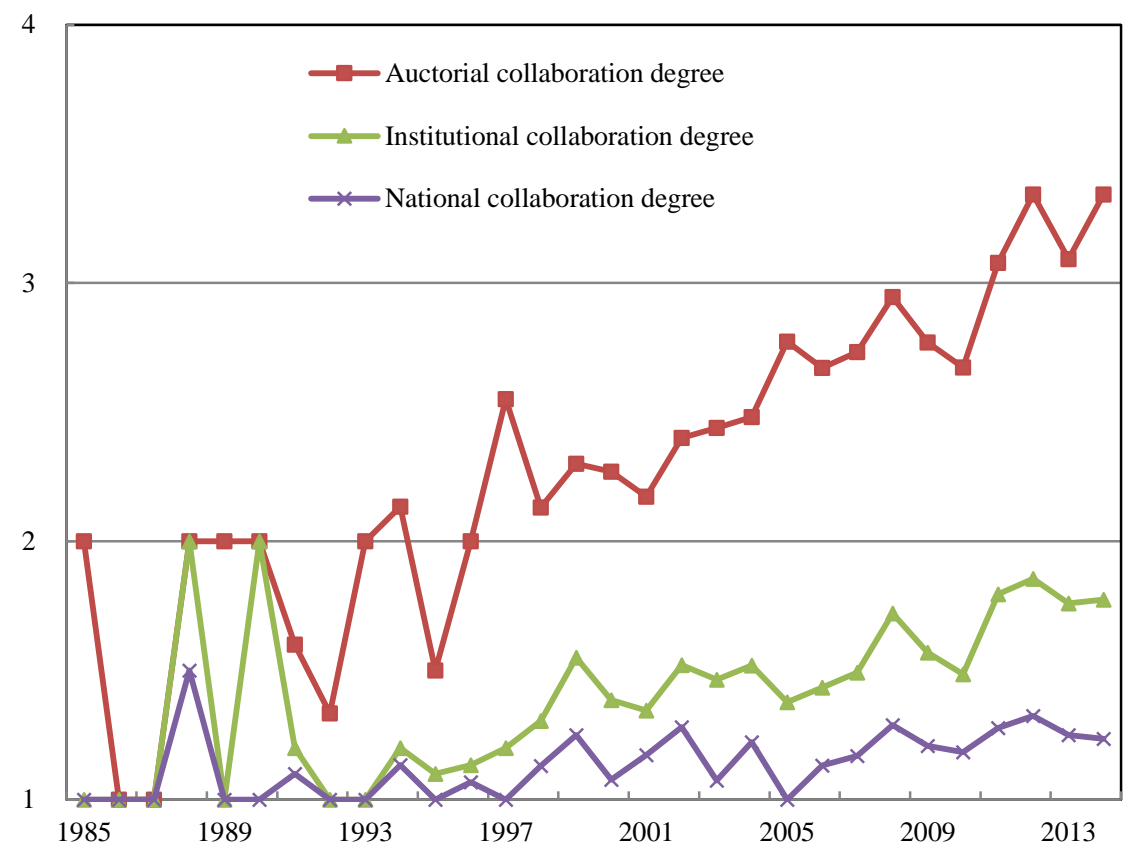

Fig.5. Three levels of collaboration degrees, 1985-2013 


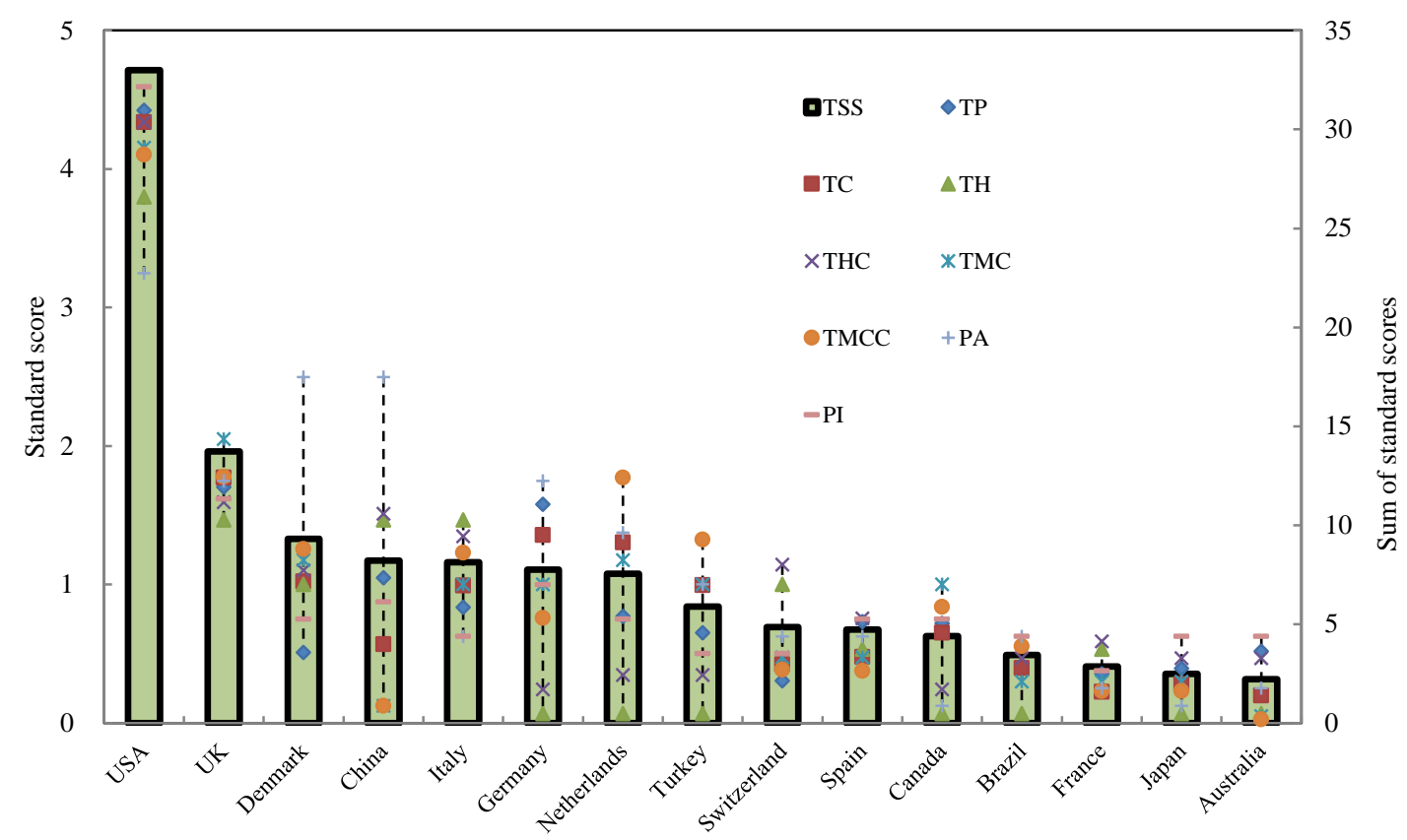

Note: TP is the number of total publications; TC is the number of total citations; TH is the number of total hot articles; THC is the number of citations of hot articles; TMC is the number of total most cited articles; TMCC is the number of total most cited articles' citations; PA is the number of productive authors; PI is the number of productive institutions; TSS is the total standard score.

Fig.6. The national comprehensive strength, 1985-2014 


\section{List of Table Captions:}

Table 1 The top 15 productive countries, 1985-2014

Table 2 The top 15 productive journals, 1985-2014

Table 3 The 15 most productive subjects, 1985-2014

Table 4 The top 15 productive authors, 1985-2014

Table 5 The top 15 productive institutions, 1985-2014

Table 6 The top 15 frequently cited articles, 1985-2014

Table 7 The frequently used keywords, 1991-2013 
Table 1

The top 15 productive countries, 1985-2014

\begin{tabular}{|c|c|c|c|c|c|}
\hline Rank & Country & $\mathbf{T P}$ & $\operatorname{TP} \mathbf{R}(\%)$ & H-index & TP A (million) \\
\hline 1 & USA & 472 & 22.25 & 32 & 7.61 \\
\hline 2 & UK & 229 & 8.96 & 23 & 2.02 \\
\hline 3 & Germany & 177 & 8.35 & 21 & 1.44 \\
\hline 4 & China & 122 & 5.75 & 14 & 1.45 \\
\hline 5 & Italy & 100 & 4.72 & 17 & 0.90 \\
\hline 6 & Netherlands & 94 & 4.43 & 20 & 0.56 \\
\hline 7 & Spain & 89 & 4.2 & 13 & 0.63 \\
\hline 8 & Canada & 88 & 4.15 & 14 & 1.08 \\
\hline 9 & Turkey & 84 & 3.96 & 16 & 0.25 \\
\hline 10 & Sweden & 83 & 3.91 & 19 & 0.42 \\
\hline 11 & Greece & 71 & 3.35 & 19 & 0.15 \\
\hline 12 & Australia & 67 & 3.16 & 10 & 0.68 \\
\hline 13 & Denmark & 66 & 3.11 & 18 & 0.22 \\
\hline 14 & Brazil & 55 & 2.59 & 11 & 0.34 \\
\hline 15 & Japan & 54 & 2.55 & 10 & 1.72 \\
\hline
\end{tabular}

Note: TP is the number of total publications; TP R $\%)$ is the ratio of the number of one country's publications to the total number of publications in the world. TP A is the total publication in all areas from Science Citation Index Expanded (1981-present) and Social Sciences Citation Index (2002-present) with the document type and language as "article" and "English" during 1985 and 2013, respectively. 
Table 2

The top 15 productive journals, 1985-2014

\begin{tabular}{clccccc}
\hline Rank & Journal & TP & TP R(\%) & IF & TC & CPP \\
\hline $\mathbf{1}$ & Energy Policy & 421 & 19.85 & 2.743 & 4622 & 10.98 \\
$\mathbf{2}$ & Renewable Energy & 125 & 5.89 & 2.989 & 996 & 7.97 \\
$\mathbf{3}$ & Energy & 102 & 4.81 & 3.651 & 1087 & 10.66 \\
$\mathbf{4}$ & Applied Energy & 79 & 3.72 & 4.781 & 624 & 7.9 \\
$\mathbf{5}$ & Energy Conversion and Management & 58 & 2.73 & 2.775 & 733 & 12.64 \\
$\mathbf{6}$ & Biomass Bioenergy & 49 & 2.31 & 2.975 & 967 & 19.73 \\
$\mathbf{6}$ & Energy Economics & 49 & 2.31 & 0.788 & 435 & 8.88 \\
$\mathbf{8}$ & Solar Energy & 30 & 1.41 & 2.952 & 414 & 13.80 \\
$\mathbf{9}$ & IEEE Transactions on Power Systems & 27 & 1.27 & 2.921 & 109 & 4.04 \\
$\mathbf{1 0}$ & International Journal of Hydrogen Energy & 24 & 1.13 & 3.548 & 394 & 16.42 \\
$\mathbf{1 1}$ & Climate Policy & 19 & 0.90 & 1.536 & 66 & 3.47 \\
$\mathbf{1 2}$ & International Journal of Energy Research & 19 & 0.90 & 1.987 & 156 & 8.21 \\
$\mathbf{1 3}$ & International Journal of Greenhouse Gas & & & & & 15.32 \\
$\mathbf{1 4}$ & Control & Energy and Buildings & 0.90 & 3.944 & 291 & 15.32 \\
$\mathbf{1 5}$ & Journal of Cleaner Production & 18 & 0.85 & 2.679 & 119 & 6.61 \\
\hline Note: TP is the number of total publications; R(\%) is the ratio of the number of one journal's publications to the total number of \\
publication; IF is impact factor; TC is the number of total citations; CPP is citations per publication.
\end{tabular}


Table3

The 15 most productive subjects, 1985-2014

\begin{tabular}{llll}
\hline Rank & Subject & TP & TP R(\%) \\
\hline $\mathbf{1}$ & Energy Fuels & 1224 & 57.52 \\
$\mathbf{2}$ & Environmental Sciences Ecology & 703 & 33.04 \\
$\mathbf{3}$ & Engineering & 518 & 24.34 \\
$\mathbf{4}$ & Thermodynamics & 193 & 9.07 \\
$\mathbf{5}$ & Business Economics & 183 & 8.6 \\
$\mathbf{6}$ & Agriculture & 108 & 5.08 \\
$\mathbf{7}$ & Biotechnology Applied Microbiology & 90 & 4.23 \\
$\mathbf{8}$ & Physics & 79 & $\square .71$ \\
$\mathbf{9}$ & Nuclear Science Technology & 78 & 3.67 \\
$\mathbf{1 0}$ & Mechanics & 72 & 3.38 \\
$\mathbf{1 1}$ & Public Administration & 59 & 2.77 \\
$\mathbf{1 2}$ & Water Resources & 45 & 2.12 \\
$\mathbf{1 3}$ & Chemistry & 42 & 1.97 \\
$\mathbf{1 4}$ & Electrochemistry & 34 & 1.6 \\
$\mathbf{1 5}$ & Operations Research Management Science & 33 & 1.55 \\
\hline
\end{tabular}

Note: TP is the number of total publications; $\mathrm{R}(\%)$ is the ratio of the number of one subject's publications to the total number of publications. 
Table 4

The top 15 productive authors, 1985-2014

\begin{tabular}{ccccccc}
\hline Rank & Authors & Country & TP & TC & CPP & H-index \\
\hline $\mathbf{1}$ & LUND H & Denmark & 13 & 612 & 47.08 & 12 \\
$\mathbf{2}$ & KALDELLIS JK & Greece & 12 & 233 & 19.42 & 8 \\
$\mathbf{3}$ & FAAIJ A & Netherlands & 10 & 256 & 25.60 & 7 \\
$\mathbf{3}$ & MADLENER R & Germany & 10 & 107 & 10.70 & 5 \\
$\mathbf{5}$ & BERNTSSON T & Sweden & 9 & 92 & 10.22 & 6 \\
$\mathbf{5}$ & MEIBOM P & Denmark & 9 & 127 & 14.11 & 7 \\
$\mathbf{7}$ & DEMIRBAS A & Turkey & 8 & 422 & 52.75 & 5 \\
$\mathbf{7}$ & FUSS S & Austria & 8 & 108 & 13.50 & 5 \\
$\mathbf{7}$ & OBERSTEINER M & Austria & 8 & 149 & 18.62 & 6 \\
$\mathbf{1 0}$ & BAKER E & USA & 7 & 63 & 9.00 & 4 \\
$\mathbf{1 0}$ & SZOLGAYOVA J & Austria & 7 & 108 & 15.43 & 5 \\
$\mathbf{1 2}$ & DINCER I & Austria & 6 & 214 & 35.67 & 5 \\
$\mathbf{1 2}$ & FERRAO P & Portugal & 6 & 36 & 6 & 4 \\
$\mathbf{1 2}$ & HARVEY S & Sweden & 6 & 62 & 10.33 & 4 \\
$\mathbf{1 2}$ & JIN HG & China & 6 & 37 & 6.17 & 3 \\
\hline
\end{tabular}

Note: Country refers to the country where the first institution of the author's latest paper is located in; TP is the number of total publications; TC is the number of total citations; CPP is citations per publication. 
Table 5

The top 15 productive institutions, 1985-2014

\begin{tabular}{|c|c|c|c|c|c|c|}
\hline Rank & Institution & Country & $\mathbf{T P}$ & $\operatorname{TP} \operatorname{RC}(\%)$ & $\begin{array}{c}\mathbf{T P} \\
\mathbf{R W}(\%)\end{array}$ & H-index \\
\hline 1 & $\begin{array}{l}\text { National Technical University of } \\
\text { Athens }\end{array}$ & Greece & 28 & 39.44 & 1.32 & 12 \\
\hline 2 & Chinese Academy of Sciences & China & 23 & 18.85 & 1.08 & 7 \\
\hline 2 & $\begin{array}{l}\text { University of California, } \\
\text { Berkeley }\end{array}$ & USA & 23 & 4.87 & 1.08 & 8 \\
\hline 2 & University of Cambridge & UK & 23 & 10.04 & 1.08 & 9 \\
\hline 2 & $\begin{array}{l}\text { Imperial College of Science, } \\
\text { Technology \& Medicine }\end{array}$ & UK & 23 & 10.04 & 1.08 & 8 \\
\hline 2 & Utrecht University & Netherlands & 23 & 24.47 & 1.08 & 10 \\
\hline 7 & $\begin{array}{l}\text { International Institute for Applied } \\
\text { Systems Analysis (IIASA) }\end{array}$ & Austria & 20 & 40.82 & 0.94 & 12 \\
\hline 8 & $\begin{array}{l}\text { Chalmers University of } \\
\text { Technology }\end{array}$ & Sweden & 19 & 22.89 & 0.90 & 9 \\
\hline 9 & Iowa State University & USA & 17 & 3.60 & 0.80 & 6 \\
\hline 9 & Polytechnic University of Milan & Italy & 17 & 17.00 & 0.80 & 7 \\
\hline 9 & Technical University of Denmark & Denmark & 17 & 25.76 & 0.8 & 7 \\
\hline 9 & Aalborg University & Denmark & 17 & 25.76 & 0.8 & 11 \\
\hline 13 & $\begin{array}{l}\text { Massachusetts Institute of } \\
\text { Technology }\end{array}$ & USA & 15 & 3.18 & 0.71 & 6 \\
\hline 13 & Tsinghua University & China & 15 & 12.30 & 0.71 & 6 \\
\hline 13 & University of Manchester & UK & 15 & 6.55 & 0.71 & 7 \\
\hline
\end{tabular}

Note: TP is the number of total publications; $\mathrm{RC}(\%)$ is the percentage of the total number of the institution to that of its country; $\mathrm{RW}(\%)$ is the percentage of the total number of the institution to that of the world. 
Table 6

The top 15 frequently cited articles, 1985-2014

\begin{tabular}{lllllll}
\hline Rank & Author & Year & Country & TC & Journal \\
\hline $\mathbf{1}$ & Demirbas [43] & 2007 & Turkey & 223 & Energy Policy \\
$\mathbf{2}$ & Hamelinck and Faaij & 2002 & Netherlands & 180 & Journal of Power Sources \\
& [44] & & & & \\
$\mathbf{3}$ & Brabec et al. [45] & 2005 & Germany & 162 & MRS Bulletin \\
$\mathbf{4}$ & Nepstad et al. [46] & 2008 & USA & 147 & Philosophical Transactions of the \\
& & & & & Royal Society B-Biological Sciences \\
$\mathbf{5}$ & Caputo et al. [47] & 2005 & Italy & 145 & Biomass \& Bioenergy \\
$\mathbf{6}$ & Lund [42] & 2005 & Denmark & 143 & Energy \\
$\mathbf{7}$ & Burney et al. [48] & 2010 & USA & 131 & Proceedings of the National Academy \\
& & & & & of Sciences of the United States of \\
& & & & & America \\
$\mathbf{8}$ & Demirbas [49] & 2001 & Turkey & 126 & Energy Conversion and Management \\
$\mathbf{9}$ & Enriquez et al. [50] & 2005 & Mexico & 121 & Limnology and Oceanography \\
$\mathbf{1 0}$ & Bhowmik et al. [51] & 1999 & USA & 114 & IEEE Transactions on Industry \\
& & & & & Applications & \\
$\mathbf{1 1}$ & Hammerschlag [52] & 2006 & USA & 110 & Environmental Science \& Technology \\
$\mathbf{1 2}$ & de Vries et al. [53] & 2007 & Netherlands & 104 & Energy Policy \\
$\mathbf{1 2}$ & Junginger et al. [54] & 2005 & Netherlands & 104 & Energy Policy \\
$\mathbf{1 4}$ & Bresesti et al. [55] & 2007 & Italy & 103 & IEEE Transactions on & Energy \\
& & & & & Conversion & \\
$\mathbf{1 5}$ & Foxon et al. [56] & 2005 & UK & 97 & Energy Policy & \\
\hline
\end{tabular}

Note: TC is the number of total citations; Country refers to the country where the first institution of the corresponding author is located in. 
Table 7

The frequently used keywords, 1991-2013

\begin{tabular}{|c|c|c|c|c|c|c|}
\hline Rank & Keyword & $\begin{array}{l}\text { Total } \\
\text { frequency }\end{array}$ & $\begin{array}{l}1994- \\
1998\end{array}$ & $\begin{array}{l}1999- \\
2003\end{array}$ & $\begin{array}{l}2004- \\
2008\end{array}$ & $\begin{array}{l}2009- \\
2013\end{array}$ \\
\hline 1 & Renewable energy & 255 & 4 & 17 & 48 & 186 \\
\hline 2 & Wind energy & 132 & 1 & 10 & 28 & 93 \\
\hline 3 & Biofuel & 111 & 3 & 1 & 11 & 96 \\
\hline 4 & $\begin{array}{l}\text { Electricity(market/generation/se } \\
\text { ctor) }\end{array}$ & 76 & 0 & 5 & 23 & 48 \\
\hline 5 & Climate change (mitigation) & 60 & 2 & 1 & 10 & 47 \\
\hline 6 & Biomass energy & 59 & 2 & 5 & 11 & 41 \\
\hline 7 & Carbon capture and storage & 58 & 0 & 0 & 6 & 52 \\
\hline 8 & Solar energy & 56 & 6 & 6 & 6 & 38 \\
\hline 9 & Sustainable development & 50 & 1 & 6 & 9 & 34 \\
\hline 10 & Real option approach & 46 & 0 & 1 & 12 & 33 \\
\hline 11 & Investment & 44 & 0 & 4 & 13 & 27 \\
\hline 12 & Photovoltaic & 42 & 1 & 2 & 7 & 32 \\
\hline 13 & Energy efficiency & 40 & 0 & 4 & 12 & 24 \\
\hline 14 & $\mathrm{CO}_{2}$ emission & 39 & 3 & 1 & 11 & 24 \\
\hline 15 & Optimization & 38 & 0 & 1 & 6 & 31 \\
\hline 16 & Energy policy & 37 & 2 & 2 & 6 & 27 \\
\hline 17 & Feed-in tariff & 36 & 0 & 0 & 4 & 32 \\
\hline 18 & Nuclear power & 34 & 0 & 2 & 9 & 23 \\
\hline 19 & China & 33 & 1 & 3 & 5 & 24 \\
\hline 20 & Uncertainty & 30 & 0 & 1 & 8 & 21 \\
\hline
\end{tabular}

Note: The total frequency is the sum of frequencies of the keyword, its abbreviations, singular or plural, gerund and so on.

\footnotetext{
5 The keywords began to be used in 1991.
} 